\section{Have your say to win a MacBook Pro}

The British Dental Association (BDA) is inviting all Essential, Extra and Expert members to take part in its 2019 Membership Survey.

Tell the BDA how is it performing, where it can do more and what it can do to improve the benefits and services that are provided to members.

Members can complete the survey either online or on paper simply look for an email or letter sent to you from BDA Research regarding the membership survey and you can access your unique link or a paper version of the survey.

This survey will take approximately 15-20 minutes to complete.

The deadline for the prize draw has now been extended, so all members who submit completed responses to the BDA by Friday 29 November 2019 will receive the chance to win a MacBook Pro.

Your responses will be anonymised and all information provided will remain confidential to the BDA.

If you would like to know more about the survey or have not received your invitation, please email Research@bda.org.

\section{Share oral health knowledge} \section{far and wide}

Can you help share oral health knowledge with low resource communities around the world?

Teeth Relief is giving away free hard copies of its Oral health manual in exchange for feedback, via their online survey: https://www.surveymonkey. co.uk/r/2LFC689.

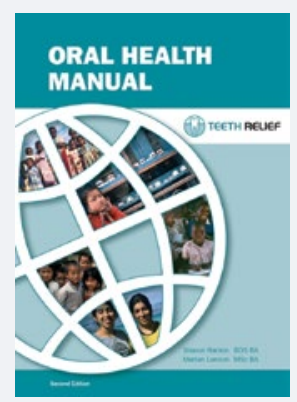

If you plan to work or volunteer around oral health in a low resource setting, why not take a copy of the manual with you? Alternatively, if you have contact with overseas health workers or educators in local programmes, you could send them a copy.

The Teeth Relief Oral Health Manual gives sound advice on oral health promotion and oral urgent treatment, designed to support the training of clinical and non-clinical healthcare workers in low resource settings. It is written in Plain English and offers a practical interpretation of the World Health Organisation's Basic Package of Oral Care.

Dame Claire Bertschinger, course leader at London School of Hygiene and Tropical Medicine, said: 'I could have done with a copy of the Teeth Relief manual when I was working for the Red Cross in Ethiopia. The cook for the children's feeding centre died from acute septicaemia after his tooth was extracted at the local medical centre with a pair of rusty pliers.'

To order your free copy go to www.stephenhancocks.com - all you pay for is the p\&p at $£ 2.95 /$ copy. Teeth Relief, a registered charity since 1989, is run entirely by volunteers. To find out more or make a donation please go to: www.teethrelief.org.uk.

\title{
Peter Ward to retire from the BDA
}

Peter Ward, British Dental Association (BDA) Chief Executive of 14 years, has announced his retirement from 31 March 2020. Most recently Peter has overseen the development and roll-out of the new BDA Indemnity product.

He will continue to work in that part of the business until his departure next year.

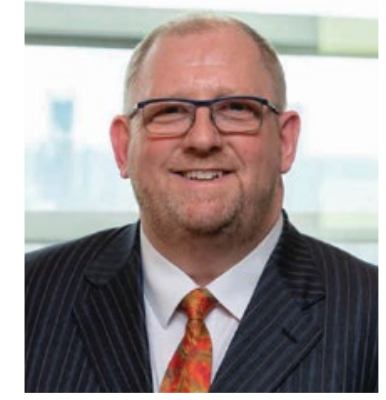

Martin Woodrow will continue as Acting Chief Executive until a permanent appointment is made.

Peter Ward said: 'Serving as Chief Executive of my own profession's representative association has been the greatest honour of my working life. My passion for the wellbeing of hard working conscientious dentists remains undiluted.

'It has been a great privilege to play an active part in supporting the UK dental profession. The pinnacle of that has been the successful launch of BDA Indemnity - an industry best product, built solely around the needs of dentists.

'With Indemnity firmly established and growing fast, I'm confident that now is the time to make room for new blood to take the BDA to new heights.'

\section{Here has been an advertisement.}

\section{SPRINGERNATURE}

